\title{
Nifedipine increases energy expenditure by increasing PGC-1 $\alpha$ expression in skeletal muscle
}

\author{
Zhe Tian ${ }^{1,2,5}$, Keishi Miyata ${ }^{1,3,5}$, Mitsuhisa Tabata ${ }^{1}$, Masato Yano ${ }^{1}$, Hirokazu Tazume ${ }^{1,2}$, Jun Aoi ${ }^{1}$, \\ Otowa Takahashi ${ }^{1}$, Kimi Araki ${ }^{4}$, Michio Kawasuji ${ }^{2}$ and Yuichi Oike ${ }^{1}$
}

Nifedipine, an L-type calcium (Ca) channel blocker, is one of the most widely used Ca channel-blocking medications for hypertension. Previous studies have reported an association of nifedipine hypertensive treatment with decreased body weight in obese hypertensive humans and rat models. However, the precise mechanism underlying how nifedipine functions metabolically has not been elucidated. Here, we investigated the long-term effect of a non-hypotensive nifedipine dose using a mildly obese, endothelial NO synthase-deficient mouse model. Treating these mice with nifedipine decreased their body weight gain ratio, and white adipose tissue weight compared with the untreated controls. Metabolic analyses indicated that nifedipine treatment upregulated whole-body energy expenditure through increasing oxygen consumption and reducing the respiratory exchange ratio, suggesting that nifedipine promotes lipid oxidation rather than carbohydrate utilization. Furthermore, nifedipine treatment upregulated the expression of the peroxisome proliferator-activated receptor- $\gamma$ coactivator $-1 \alpha$ (PGC-1 $\alpha)$ in skeletal muscle. Overall, these results suggest that a non-hypotensive dose of nifedipine has pleiotropic effects on energy expenditure that could ameliorate obesity.

Hypertension Research (2011) 34, 1221-1227; doi:10.1038/hr.2011.129; published online 4 August 2011

Keywords: lipid oxidation; nifedipine; obesity; skeletal muscle

\section{INTRODUCTION}

Obesity, the most prevalent nutritional disorder in industrialized countries, is a challenging medical problem associated with increased risks of hypertension, cardiovascular disease, hyperlipidemia, diabetes and mortality. Obesity is defined as excess body fat accumulation and results from a daily energy imbalance, such as excess calorie intake and/ or decreased energy consumption. Thus, restoring energy expenditure is considered as an efficient strategy for preventing or treating obesity.

Skeletal muscle is a massive organ accounting for $40-50 \%$ of the total body mass and thus significantly expends whole-body energy expenditure even under sedentary conditions. In particular, lipid oxidation in skeletal muscle is critical and has received increased attention for its role in obesity. Specifically, in obese subjects, skeletal muscle has been described to reduce lipid oxidation. ${ }^{1}$ A decreased ability to oxidize lipids has been linked with weight gain as well as a propensity towards obesity. Thus, developing effective treatments that can reverse and/or compensate for impaired lipid oxidation in the skeletal muscle of obese subjects is important.

Calcium $(\mathrm{Ca})$ channel blockers are commonly used to treat patients with hypertension. Nifedipine, a widely used antihypertensive drug, is thought to act mainly by blocking dihydropyridine receptor/L-type
Ca channels on vascular smooth muscle cells. Nifedipine treatment reduces atherosclerotic plaques in cholesterol-fed rabbits, ${ }^{2,3}$ and suppresses development and progression of atherosclerosis in hypertensive patients. ${ }^{4,5}$ Nifedipine has recently been reported to have pleiotropic effects on endothelial cells, ${ }^{6,7}$ cardiac muscle cells, ${ }^{8,9}$ mesangial cells ${ }^{10-12}$ and neurons, ${ }^{13,14}$ through mechanisms independent of blocking Ca channels. Previous studies have reported that nifedipine treatment decreases body weight in obese hypertensive humans ${ }^{15}$ and rat models. ${ }^{16}$ These data suggest that antihypertensive doses of nifedipine alter fat metabolism associated with anti-obesity. Interestingly, Iwai et al. ${ }^{17}$ recently reported that a non-hypotensive dose of nifedipine decreased the weight of white adipose tissue (WAT) and enhanced insulin sensitivity in obese diabetic KK- $\mathrm{A}^{\mathrm{y}}$ mice, suggesting that such treatment directly impacts fat metabolism. Nonetheless, the mechanism through which nifedipine treatment modulates energy expenditure has not been fully elucidated.

In this study, we examined the long-term effect of a non-hypotensive dose of nifedipine on mildly obese model mice in which endothelial NO synthase (eNOS) was deficient. Nifedipine treatment antagonized weight gain, and increased whole-body energy expenditure and lipid oxidation in skeletal muscle. Interestingly, we also observed an increase

${ }^{1}$ Department of Molecular Genetics, Graduate School of Medical Sciences, Kumamoto University, 1-1-1 Honjo, Kumamoto, Japan; ${ }^{2}$ Department of Cardiovascular Surgery, Graduate School of Medical Sciences, Kumamoto University, 1-1-1 Honjo, Kumamoto, Japan; ${ }^{3}$ Department of Immunology, Allergy and Vascular Medicine, Graduate School of Medical Sciences, Kumamoto University, 1-1-1 Honjo, Kumamoto, Japan and ${ }^{4}$ Division of Developmental Genetics, Center for Animal Resources and Development, Kumamoto University, 2-2-1 Honjo, Kumamoto, Japan ${ }^{5}$ These authors contributed equally to this work.

Correspondence: Dr K Miyata, Department of Immunology, Allergy and Vascular Medicine, Graduate School of Medical Sciences, Kumamoto University, 1-1-1 Honjo, Kumamoto 860-8556, Japan. 
in peroxisome proliferator-activated receptor- $\gamma$ coactivator- $1 \alpha$ (PGC- $1 \alpha)$ expression in skeletal muscle of nifedipine-treated eNOS-deficient mice. These results indicate that nifedipine pleiotropically increases energy expenditure and could thereby counteract obesity.

\section{METHODS}

Animals

All experimental protocols were approved by the Kumamoto University Ethics Review Committee for Animal Experimentation. Male eNOS-deficient mice on

Table 1 Primer sequences used in quantitative RT-PCR

\begin{tabular}{|c|c|c|}
\hline Gene & & Sequences \\
\hline \multirow[t]{2}{*}{$\beta$-Actin } & Forward & 5'-CATCCGTAAAGACCTCTATGCCAAC-3' \\
\hline & Reverse & 5'-ATGGAGCCACCGATCCACA-3' \\
\hline \multirow[t]{2}{*}{ CD31 } & Forward & 5'-CCGAAGCAGCACTCTTGCAG-3' \\
\hline & Reverse & 5'-CTGCAACTATTAAGGTGGCGATGA-3' \\
\hline \multirow[t]{2}{*}{ PGC-1 $\alpha$} & Forward & 5'-CCGTAAATCTGCGGGATGATG-3' \\
\hline & Reverse & 5'-CAGTTTCGTTCGACCTGCGTAA-3' \\
\hline \multirow[t]{2}{*}{ PGC-1 $\beta$} & Forward & 5'-GTGCCAGGTGCTGACGAGAA-3' \\
\hline & Reverse & 5'-AGTGTATCTGGGCCAACGGAAG-3' \\
\hline \multirow[t]{2}{*}{ PPAR $\alpha$} & Forward & 5'-ACGCTCCCGACCCATCTTTAG-3' \\
\hline & Reverse & 5'-TCCATAAATCGGCACCAGGAA-3' \\
\hline \multirow[t]{2}{*}{ PPAR $\delta$} & Forward & 5'-CAGATGACCCTTGTGCTGCCTA-3' \\
\hline & Reverse & 5'-TCTGACCCTGGGACCTAAGTGTG-3' \\
\hline \multirow[t]{2}{*}{ Tie2 } & Forward & 5'-TGCCCAGATATTGGTGTCCTTAAAC-3' \\
\hline & Reverse & 5'-TCCGCAGGGCAGTCAATTC-3' \\
\hline \multirow[t]{2}{*}{ UCP2 } & Forward & 5'-GCAAGCATGTGTATGGCACAGTAAC-3' \\
\hline & Reverse & 5'-AAATGTGGGCCTTCGGTCAG-3' \\
\hline \multirow[t]{2}{*}{ UCP3 } & Forward & 5'-GTGGTAAAGCCATGCACACCTG-3' \\
\hline & Reverse & 5'-CCTGCTGCTTTGAACTGATGGA-3' \\
\hline \multirow[t]{2}{*}{ VE-cadherin } & Forward & 5'-TGGCTTGTCGAATTTGAAGCA-3' \\
\hline & Reverse & 5'-TCTGGTGAGTGGGTTAGAGGCTATC-3' \\
\hline \multirow[t]{2}{*}{ CD36 } & Forward & 5'-GATGGCCTTACTTGGGATTGGA-3' \\
\hline & Reverse & 5'-GGCTTTACCAAAGATGTAGCCAGTG-3' \\
\hline \multirow[t]{2}{*}{ FATP1 } & Forward & 5'-GCAGCATTGCCAACATGGAC-3' \\
\hline & Reverse & 5'-GTGTCCTCATTGACCTTGACCAGA-3' \\
\hline \multirow[t]{2}{*}{ ACSL1 } & Forward & 5'-TTTGCCTGCAGCGAGTGTG-3' \\
\hline & Reverse & 5'-GCCCTCGACTATCCCTATGGTAAGA-3' \\
\hline \multirow[t]{2}{*}{ FABP3 } & Forward & 5'-TGGCTAGCATGACCAAGCCTACTAC-3' \\
\hline & Reverse & 5'-GTTCCACTTCTGCACATGGATGA-3' \\
\hline \multirow[t]{2}{*}{ CPT1-b } & Forward & 5'-GAGACAGGACACTGTGTGGGTGA-3' \\
\hline & Reverse & 5'-AGTGCCTTGGCTACTTGGTACGAG-3' \\
\hline \multirow[t]{2}{*}{ ACADS } & Forward & 5'-AAGTTTGGATCCGCACAGCAG-3' \\
\hline & Reverse & 5'-CAAGCTTTGGTGCCGTTGAG-3' \\
\hline \multirow[t]{2}{*}{ ACADM } & Forward & 5'-CGAGTATGTTATCAACGGCCAGAA-3' \\
\hline & Reverse & 5'-GCGGGTACTTTAGGATCTGGGTTAG-3' \\
\hline \multirow[t]{2}{*}{ ACADL } & Forward & 5'-GGACTCCGGTTCTGCTTCCA-3' \\
\hline & Reverse & 5'-TGCAATCGGGTACTCCCACA-3' \\
\hline \multirow[t]{2}{*}{ ACOX1 } & Forward & 5'-AAGATGGATCCTAAGCCAGCTGAA-3' \\
\hline & Reverse & 5'-CAGCTTACCACAAAGCCAGCTACTC-3' \\
\hline \multirow[t]{2}{*}{ ACOX2 } & Forward & 5'-CTGGGCTCAGATGAGCAGATTG-3' \\
\hline & Reverse & 5'-ACTCCTGGGTGGTTGCATCATAG-3' \\
\hline \multirow[t]{2}{*}{ Acaala } & Forward & 5'-TTCACGGCAGAAGCAGGATG-3' \\
\hline & Reverse & 5'-CACAATCTCAGCACGGAAGCA-3' \\
\hline \multirow[t]{2}{*}{ MFP2 } & Forward & 5'-GCAGCATGGGACCATATGAAGA-3' \\
\hline & Reverse & 5'-ATGCCCAGCTTTGCAGCAC-3' \\
\hline
\end{tabular}

Abbreviations: Acaala, acetyl-CoA acyltransferase 1A; ACADL, acyl-CoA dehydrogenase, long chain; ACADM, acyl-CoA dehydrogenase, medium chain; ACADS, acyl-CoA dehydrogenase, short chain; ACOX, acyl-CoA oxidase; ACSL1, acyl-CoA synthetase long-chain family member 1; CD, cluster of differentiation. CPT1b, carnitine palmitoyl-transferase 1B. FABP, fatty acid binding protein. FATP1, fatty acid transport protein 1; MFP2, multifunctional protein 2; PGC1, proliferator-activated receptor- $\gamma$ coactivator -1 ; PPAR, peroxisome proliferator-activated receptor; UCP, uncoupling protein; VE-cadherin, vascular endothelial cadherin. a C57BL/6N background were used for all experiments. All animals were bred in a mouse house with automatically controlled lighting ( $12 \mathrm{~h} \mathrm{on}, 12 \mathrm{~h}$ off), and a stable temperature of $23^{\circ} \mathrm{C}$ was maintained throughout. Mice were fed a normal diet (CE-2, CLEA, Tokyo, Japan).

\section{Nifedipine treatment}

Mice were divided into two groups (10 per group) and implanted with a mini-osmotic pump (Alzet Corp. Mini-osmotic pump, Model 2002, Palo Alto, CA, USA) in subcutaneous back tissue. Control mice were administrated a vehicle solution (polyethylene glycol 400 (WAKO, Osaka, Japan), ethanol and $\mathrm{H}_{2} \mathrm{O}$ in the ratio 15:15:70). Nifedipine was administered at doses of $1 \mathrm{mg} \mathrm{kg}^{-1}$ per day in the vehicle solution (Bayer Yakuhin, Ltd, Osaka, Japan).

\section{Metabolic measurements}

Mice were subjected to metabolic analysis after 16 weeks of administration of either nifedipine or control vehicle. Insulin and glucose tolerance tests (ITT and GTT, respectively) were performed as previously described. ${ }^{18}$ For ITT, mice were administered $1.0 \mathrm{U} \mathrm{kg}^{-1}$ of human insulin by intraperitoneal injection. For GTT, mice were deprived of food for $16 \mathrm{~h}$ and were injected with glucose intraperitoneally at $1.25 \mathrm{~g} \mathrm{~kg}^{-1}$. Serum glucose was measured using the glucose oxidase method (Sanwa Kagaku, Nagoya, Japan), and serum insulin was measured using an insulin immunoassay (Morinaga, Yokohama, Japan). Insulin sensitivity was determined using homeostatic model assessment-insulin resistance (HOMA-IR). ${ }^{19}$ The HOMA-IR index is calculated from both fasting glucose and insulin levels as follows: HOMA-IR index $=$ fasting glucose $\left(\mathrm{mg} \mathrm{dl}^{-1}\right) \times$ fasting insulin $\left(\mu \mathrm{Uml}^{-1}\right) / 405$. Mouse adiposity was assessed by computed tomography scanning (LaTheta, Hitachi, Aloka Medical, Ltd, Tokyo, Japan) as previously described. ${ }^{18}$ Blood pressure was monitored every 4 weeks using a tail-cuff monitor (BP Monitor for Mice \& Rats Model MK-2000, Muromachi Co., Ltd, Tokyo, Japan). Oxygen consumption $\left(\mathrm{VO}_{2}\right)$, carbon dioxide production $\left(\mathrm{VCO}_{2}\right)$, the respiratory exchange ratio (RER) and activity levels were determined (Light time; 13:00-17:00, Dark time; 1:00-5:00, air flow rate $0.501 \mathrm{~min}^{-1}$ ) as previously described. ${ }^{18}$ For exercise experiments, mice were allowed to adapt to an air-tight treadmill chamber (Model MK-680AT/02 M, Muromachi Co., Ltd) for $30 \mathrm{~min}$ (air flow rate $0.901 \mathrm{~min}^{-1}$ ) at which point $\mathrm{VO}_{2}$ and $\mathrm{VCO}_{2}$ were stable; measurements were then continued for another $30 \mathrm{~min}$ while mice were in a sedentary state. Mice then exercised on a treadmill at a speed of $10 \mathrm{~m} \mathrm{~min}^{-1}$, and $\mathrm{VO}_{2}, \mathrm{VCO}_{2}$ and RER were measured for $30 \mathrm{~min}$ as previously described. ${ }^{20}$

\section{Quantitative real-time PCR}

Total RNA was isolated using TRIzol reagent (Invitrogen Japan KK, Tokyo, Japan). DNase-treated RNA was reverse transcribed using a PrimeScript RT reagent Kit (Takara Bio, Shiga, Japan). PCR products were analyzed with a Thermal Cycler Dice Real-Time system (Takara Bio), and relative transcript abundance was normalized to that of $\beta$-actin mRNA. Oligonucleotides used for PCR are listed in Table 1.

Table 2 Body weight and systolic blood pressure before (pre) and after nifedipine administration

\begin{tabular}{lccc}
\hline & $\begin{array}{c}\text { Pre } \\
\text { (8-week-old) }\end{array}$ & $\begin{array}{c}\text { 2 months } \\
\text { (16-week-old) }\end{array}$ & $\begin{array}{c}\text { 4 months } \\
\text { (20-week-old) }\end{array}$ \\
\hline $\begin{array}{l}\text { Body weight (g) } \\
\text { Control }\end{array}$ & $23.0 \pm 0.3$ & $26.7 \pm 0.6$ & $27.9 \pm 0.8$ \\
Nifedipine & $23.2 \pm 0.1$ & $26.9 \pm 0.5$ & $26.2 \pm 0.4$ \\
& & & \\
Systolic blood pressure (mm Hg) & & \\
Control & $115.7 \pm 2.2$ & $117.4 \pm 3.7$ & $118.3 \pm 6.3$ \\
Nifedipine & $112.3 \pm 1.8$ & $116.8 \pm 4.0$ & $121.1 \pm 5.5$ \\
\hline
\end{tabular}

Nifedipine was administered at $1 \mathrm{mg} \mathrm{kg}^{-1}$ per day for 4 months via an implanted osmotic pump. 


\section{Statistical analysis}

All data are expressed as the means \pm s.e.m.'s in the text and in figures. A value of $P<0.05$ was considered statistically significant.

\section{RESULTS}

Nifedipine treatment reduces adipose tissue weight and volume After 16 weeks of nifedipine treatment $\left(1 \mathrm{mg} \mathrm{kg}^{-1}\right.$ per day), neither the systolic blood pressure (Table 2) nor the heart rate (data not shown) changed significantly in eNOS-deficient mice compared with the control mice. After 16 weeks of treatment, the overall body weight of the nifedipine-treated mice did not differ significantly from the control mice, although 16 weeks of nifedipine administration trended towards a reduction $(P=0.090$, Table 2$)$. Indeed, the body weight gain ratio (increased weight per mouse body weight) of nifedipine-treated mice was significantly less than the control mice $(P=0.018$, Figure $1 \mathrm{a})$, suggesting that nifedipine treatment antagonizes body weight increases. Significant reductions in the weight of epididymal WAT and brown adipose tissue proportional to body weight were observed in nifedipine-treated mice $(P=0.0038$ and $P=0.0016$, respectively, Figure $1 \mathrm{~b}$ ), whereas the skeletal muscle weight relative to body weight

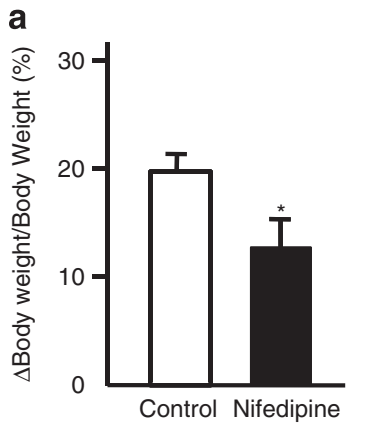

c
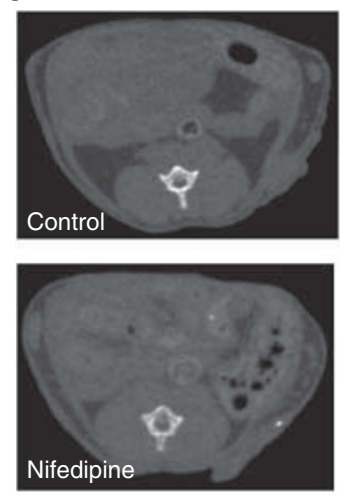
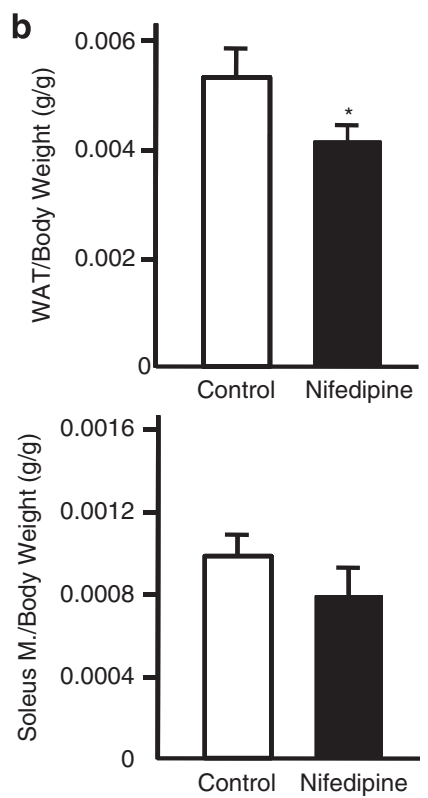

d

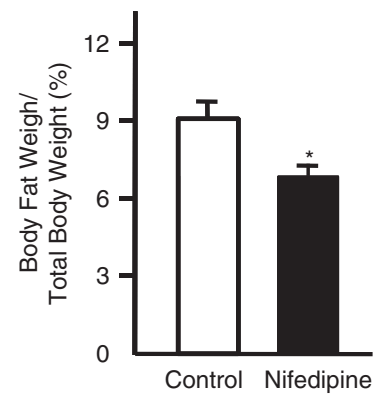

f

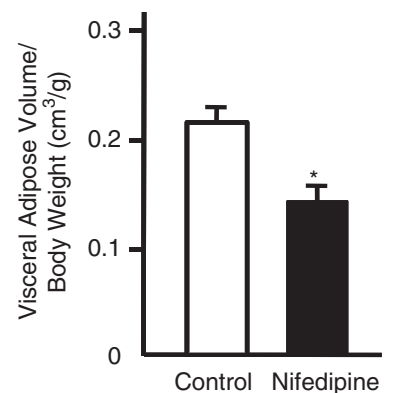

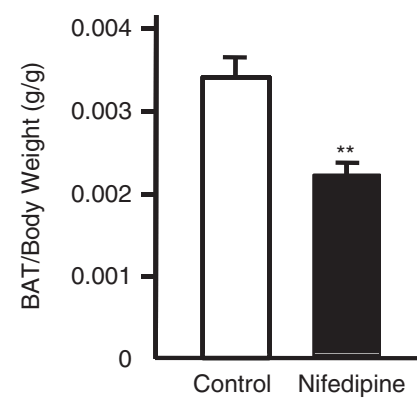
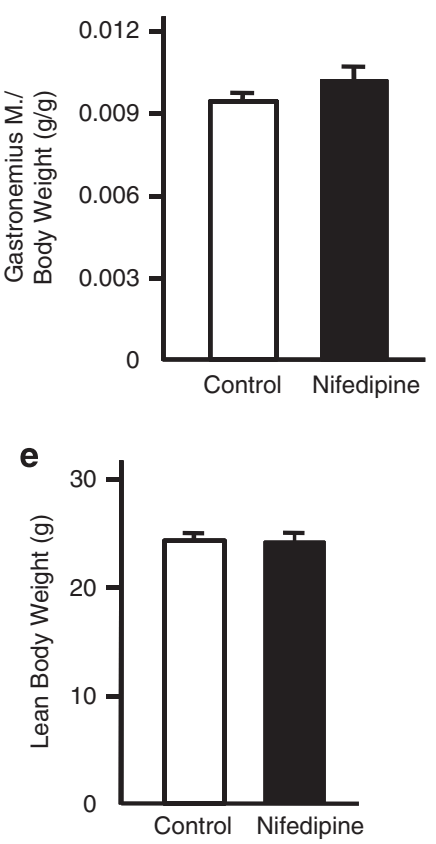

g

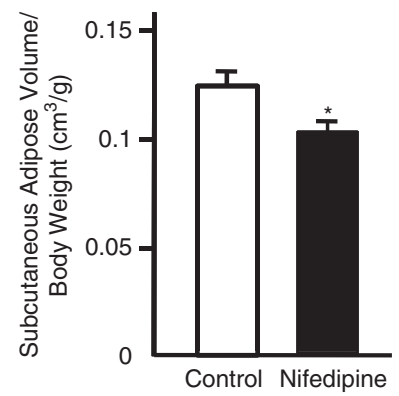

Figure 1 Effect of nifedipine on weight gain and percentage of body fat. Comparison of the ratio of body weight gain to overall body weight ( $\Delta$ Body weight/ Body weight) at the end of the 16 weeks (a) and weight of each tissue per overall body weight (b) between the control and nifedipine-treated mice ( $n=7-9$ per group). Abdominal computed tomography analysis of control (top) and nifedipine-treated (bottom) mice (c). Comparison of the percentage of body fat (Body fat weight/Total body weight) (d), lean body weight (e), visceral adipose volume per body weight (f) and subcutaneous adipose volume per body weight (g) between control and nifedipine-treated mice ( $n=7-9$ per group). ${ }^{*} P<0.05,{ }^{* *} P<0.01$ vs. control. 
was unchanged. Computed tomography scans indicated that the body fat volume of nifedipine-treated mice significantly decreased ( $P=0.021$, Figures $1 \mathrm{c}$ and $\mathrm{d}$ ), whereas the lean body weight remained unchanged (Figure 1e). Moreover, significant reductions in both visceral adipose and subcutaneous adipose volume per body weight were observed in nifedipine-treated mice $(P=0.017$ and $P=0.047$, respectively, Figures if and 1g, respectively). Taken together, these results indicate that nifedipine treatment antagonizes increases in body fat mass.

\section{Nifedipine treatment enhances oxygen expenditure and reduces the RER}

To investigate the mechanism by which nifedipine promotes WAT mass reduction, we analyzed basal metabolic rate, locomotor activity and food intake in eNOS-deficient mice (Figure 2). Nifedipine-treated mice exhibited a significant increase in whole-body $\mathrm{VO}_{2}$ rates in darktime measurements $(P=0.027$, Figure $2 \mathrm{a})$ relative to control mice, whereas no significant changes were observed in $\mathrm{VCO}_{2}$ rates (Figure $2 \mathrm{~b})$. Furthermore, the RER $\left(\mathrm{VCO}_{2} / \mathrm{VO}_{2}\right)$ of nifedipine-treated mice was significantly decreased in dark time, suggesting a greater fat utilization as an energy source $(P=0.025$, Figure $2 \mathrm{c})$. Nifedipinetreated mice exhibited a significant increase in locomotor activity

a
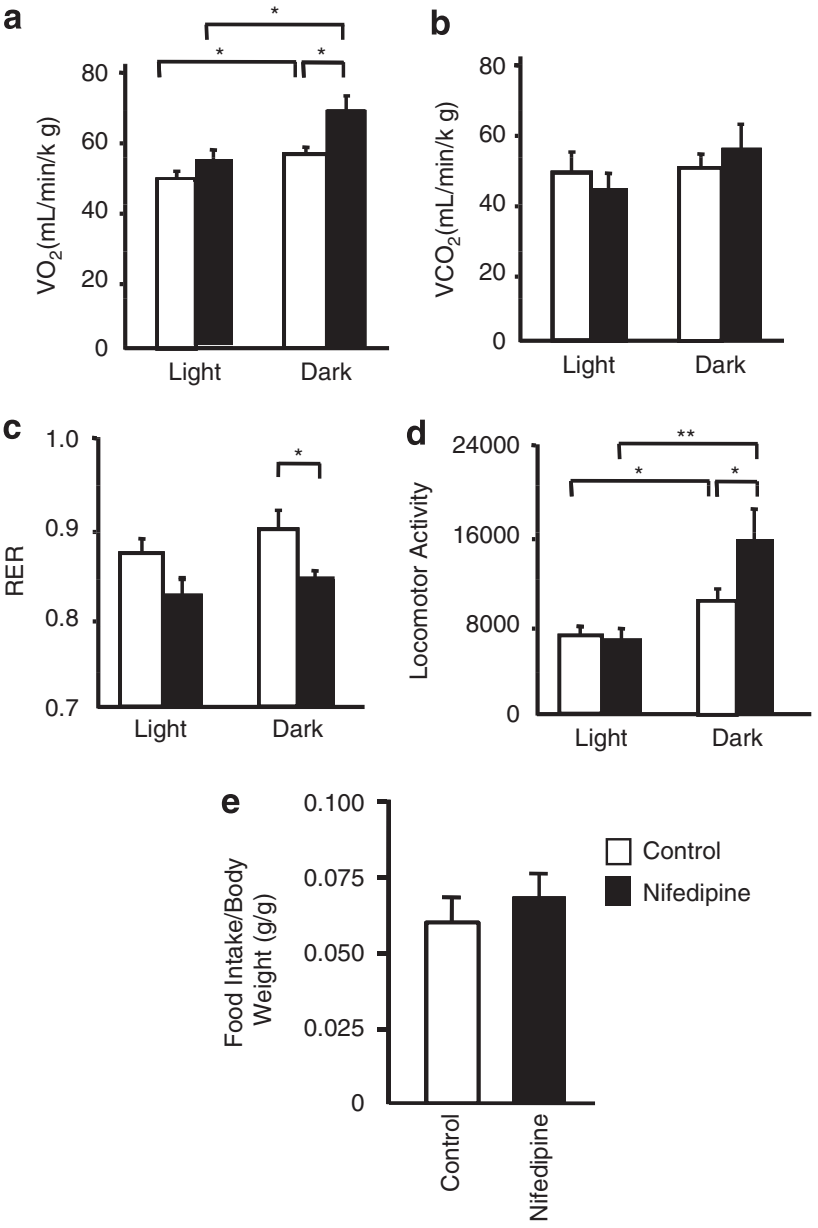

Figure 2 Effect of nifedipine on oxygen expenditure and the respiratory exchange ratio (RER). Comparison of oxygen consumption (a), carbon dioxide production (b), RER (c), locomotor activity (d) and food intake per body weight (e) between control and nifedipine-treated mice ( $n=7-8$ per group). ${ }^{*} P<0.05,{ }^{* *} P<0.01$ vs. control. compared with control mice, particularly in dark time $(P=0.044$, Figure 2d). No significant change was observed in food intake per body weight (Figure 2e) or rectal temperature (data not shown). Taken together, these results suggest that nifedipine treatment increases energy expenditure. We further investigated whether nifedipine treatment alters the oxygen consumption and carbon dioxide production during treadmill-induced exercise (Figure 3). To accomplish this, we monitored $\mathrm{VO}_{2}, \mathrm{VCO}_{2}$ and RER during $10 \mathrm{~m} \mathrm{~min}^{-1}$ treadmill running. Although no significant change was observed in $\mathrm{VO}_{2}$ (Figure $3 \mathrm{a}$ ), the $\mathrm{VCO}_{2}$ of the nifedipine-treated mice was significantly decreased (25-30 min exercise; $P=0.013$, Figure $3 \mathrm{~b}$ ) compared to controls. Interestingly, after $10 \mathrm{~min}$ of exercise, the RER of

a
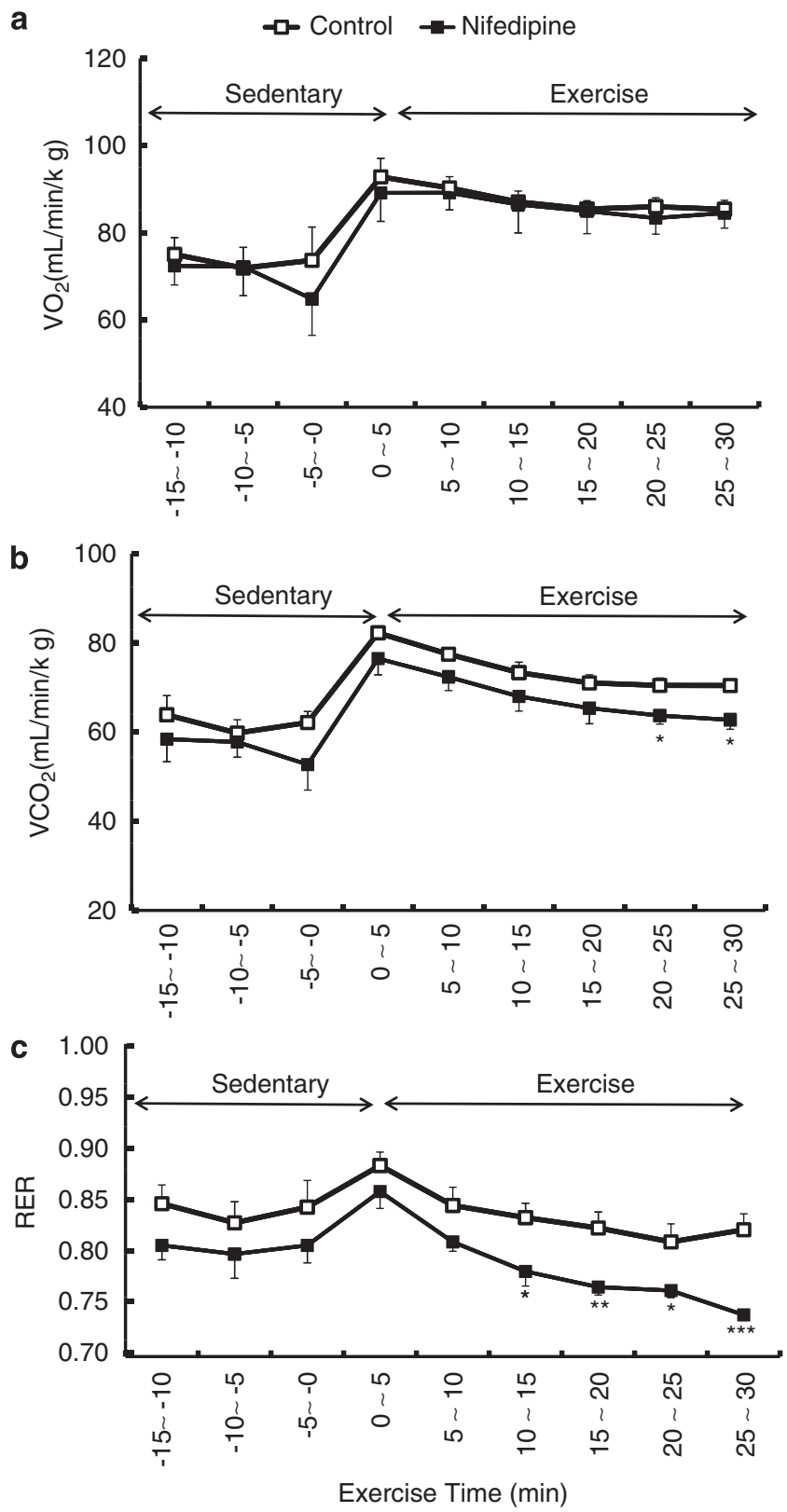

Figure 3 Effect of nifedipine on respiratory exchange ratio (RER) during exercise conditions. Comparison of oxygen consumption (a), carbon dioxide production (b) and RER during treadmill-induced exercise $\left(10 \mathrm{~m} \mathrm{~min}^{-1}\right.$ ) (c) between control and nifedipine-treated mice ( $n=6$ per group). ${ }^{*} P<0.05$, ${ }^{* *} P<0.01,{ }^{* * *} P<0.005$ vs. control. 


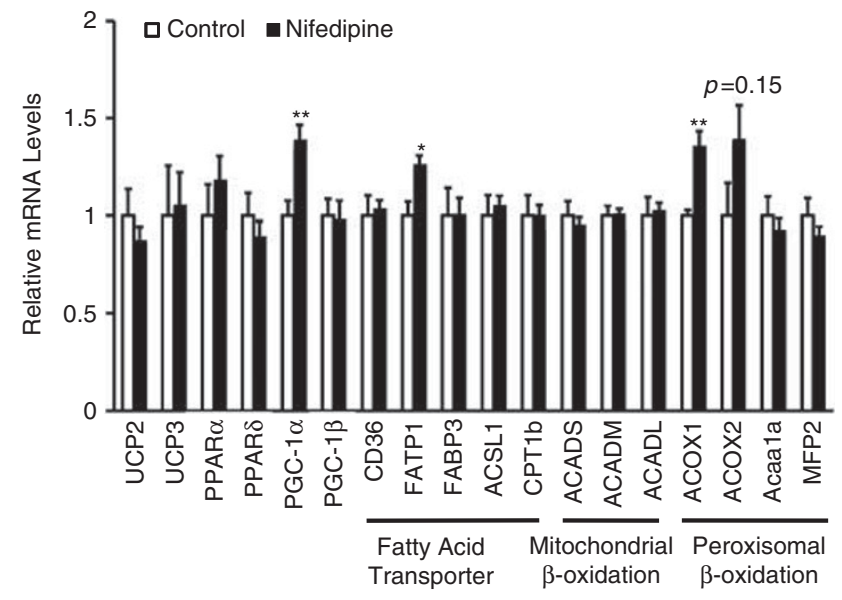

Figure 4 Effect of nifedipine on expression of markers indicating energy expenditure and fat metabolism in soleus muscle. Comparison of gene expression levels in control and nifedipine-treated mice ( $n=8$ per group). Values were normalized to that of $\beta$-actin. ${ }^{*} P<0.05,{ }^{* *} P<0.01$ vs. control. Acaala, acetyl-CoA acyltransferase 1A; ACADL, acyl-CoA dehydrogenase, long chain; ACADM, acyl-CoA dehydrogenase, medium chain; ACADS, acylCoA dehydrogenase, short chain; ACOX, acyl-CoA oxidase; ACSL1, acyl-CoA synthetase long-chain family member $1 ; C D$, cluster of differentiation; CPT1b, carnitine palmitoyl-transferase 1B; FABP, fatty acid binding protein; FATP1, fatty acid transport protein 1; MFP2, multifunctional protein 2; PPAR, peroxisome proliferator-activated receptor; UCP, uncoupling protein.

nifedipine-treated mice significantly decreased compared with control mice (25-30 min exercise; $P=0.0005$, Figure $3 c$ ). These results agree with a spontaneous activity analysis showing reduced RER in nifedipine-treated mice (see Figure 2c). We also investigated the effect of nifedipine treatment on exercise tolerance (Supplementary Figure S1) and observed no significant change in endurance capacity compared with control mice. Overall, our findings suggest that nifedipine treatment increases lipid utilization rather than carbohydrates as an energy source during both spontaneous and treadmill-induced exercise, likely leading to decreased fat tissue weight.

\section{Nifedipine treatment increases PGC-1 $\alpha$ mRNA levels and $\beta$-oxidation in skeletal muscle}

To determine the molecular basis for metabolic changes seen in nifedipine-treated mice, we undertook quantitative real-time PCR analysis to examine mRNA levels of factors regulating energy expenditure and metabolic activity in skeletal muscle using eNOS-deficient mice (Figure 4). PGC- $1 \alpha$ expression was significantly increased in the soleus muscle of nifedipine-treated mice ( $P=0.0051$, Figure 4$)$. The expression of fatty acid transport protein 1 and acyl-coenzyme A oxidase 1 , a peroxisomal $\beta$-oxidation-related gene, was significantly increased in nifedipine-treated mice compared with control mice ( $P=0.016$ and $P=0.008$, respectively, Figure 4$)$, suggesting that nifedipine-induced PGC- $1 \alpha$ in skeletal muscle may activate fat utilization by enhancing fatty acid transport and $\beta$-oxidation. Expression levels of blood vascular markers, including CD31, Tie2 and VE-cadherin, in the soleus muscle were equivalent in nifedipine-treated and untreated mice, suggesting that non-hypotensive drug doses do not induce blood vessel formation in skeletal muscle (data not shown).

\section{Nifedipine treatment increases insulin sensitivity}

It has recently been reported that nifedipine administration significantly suppresses serum insulin levels in $\mathrm{KK}-\mathrm{A}^{\mathrm{y}}$ mice, suggesting that nifedipine treatment improves hyperinsulinemia. ${ }^{17}$ Therefore, we investigated whether serum insulin or glucose levels would be altered by nifedipine treatment at the dosages outlined in the Methods section. Although nifedipine-treated mice exhibited no change in serum glucose levels, they did show lower serum insulin levels than control mice both after fasting and under ad libitum feeding conditions ( $P=0.024$ and $P=0.0032$, respectively, Figure 5a). The HOMAIR index was also significantly lower in nifedipine-treated mice $(P=0.030$, Figure 5b) than in control mice. These results indicate that nifedipine treatment promotes greater insulin sensitivity. To confirm this finding, we conducted ITT and GTT tolerance tests, and found a tendency toward increased insulin sensitivity in nifedipine-treated mice ( $P=0.089$, Figures $5 \mathrm{c}$ and $\mathrm{d}$ ). Serum glucose levels after glucose injection were significantly improved in nifedipinetreated mice compared with control mice $(P=0.021$ and $P=0.024$, respectively, Figures $5 \mathrm{e}$ and $\mathrm{f}$ ). These results suggest that the attenuation of hyperinsulinemia by nifedipine treatment may contribute to its beneficial effects on energy expenditure.

\section{DISCUSSION}

In this study, we demonstrated that long-term treatment with nonhypotensive doses of nifedipine enhances whole-body energy expenditure by increasing oxygen consumption, resulting in reduced body fat gain in mildly obese mice. In a clinical trial, Tuck et al. ${ }^{15}$ showed a significant decrease in body weight after nifedipine treatment (30$180 \mathrm{mg}$ per day orally for 3 months) in patient groups classified as obese $(\mathrm{BMI}>30)$ or overweight $(25 \leqslant \mathrm{BMI} \leqslant 30)$ with mild-to-moderate hypertension, whereas patients of normal weight $(\mathrm{BMI}<25)$ did not show decreases in body weight. By contrast, nifedipine reduced blood pressure equally well in all hypertensive patient groups. Radin et al. $^{16}$ also reported that nifedipine treatment (average dose $114 \mathrm{mg} \mathrm{kg}^{-1}$ per day in rat chow for 3 months) decreased body weight and abdominal and subcutaneous fat masses of SHHF/Mcc- $-\mathrm{fa}^{\mathrm{cp}} / \mathrm{fa}^{\mathrm{cp}}$ rats, which are a spontaneous rat model of hypertension, obesity, insulin resistance, glucose intolerance and hyperlipidemia. These reports indicate that antihypertensive doses of nifedipine treatment can decrease body weight in obese hypertensive subjects. However, it is possible that nifedipine's activity as a vasodilator at these doses promotes blood flow into skeletal muscle and enhances the fatty acid supply as an energy source to these tissues. Therefore, we investigated whether nifedipine treatment directly suppresses body weight without an antihypertensive effect. The present study revealed that nonhypotensive doses of nifedipine (a dose of $1 \mathrm{mg} \mathrm{kg}^{-1}$ per day via infusion pump for 4 months) significantly reduced epididymal WAT and body weight gain, suggesting that the nifedipine has an antiobesity effect. In agreement, Russell et al. ${ }^{21,22}$ reported that nifedipine treatment (a dose of $15 \mathrm{mg} \mathrm{kg}^{-1}$ per day in food pellets for 7.5 months) moderately decreased the body weight of JCR:LA-cp/cp rats, a normotensive obese rat model with marked hyperlipidemia and insulin resistance, indicating that nifedipine directly affects weight loss. Iwai et al. ${ }^{17}$ also reported that non-hypotensive doses of nifedipine (average dose $1.5 \mathrm{mg} \mathrm{kg}^{-1}$ per day in lab chow for 5 weeks) significantly decreased epididymal WAT weight and moderately decreased wholebody weight of obese diabetic KK-A $\mathrm{A}^{\mathrm{y}}$ mice by stimulating adipocyte differentiation. This observation strongly suggests that non-hypotensive doses of nifedipine treatment enhance fat metabolism.

The dihydropyridine receptor, a target of nifedipine, is expressed in skeletal muscle cells ${ }^{23}$ although its function in those tissues remains unknown. A previous study reported that nifedipine treatment increases fatty acid oxidation in C2C12 myotubes. ${ }^{24}$ Thus, nifedipine may directly inhibit the dihydropyridine receptor expressed in skeletal 

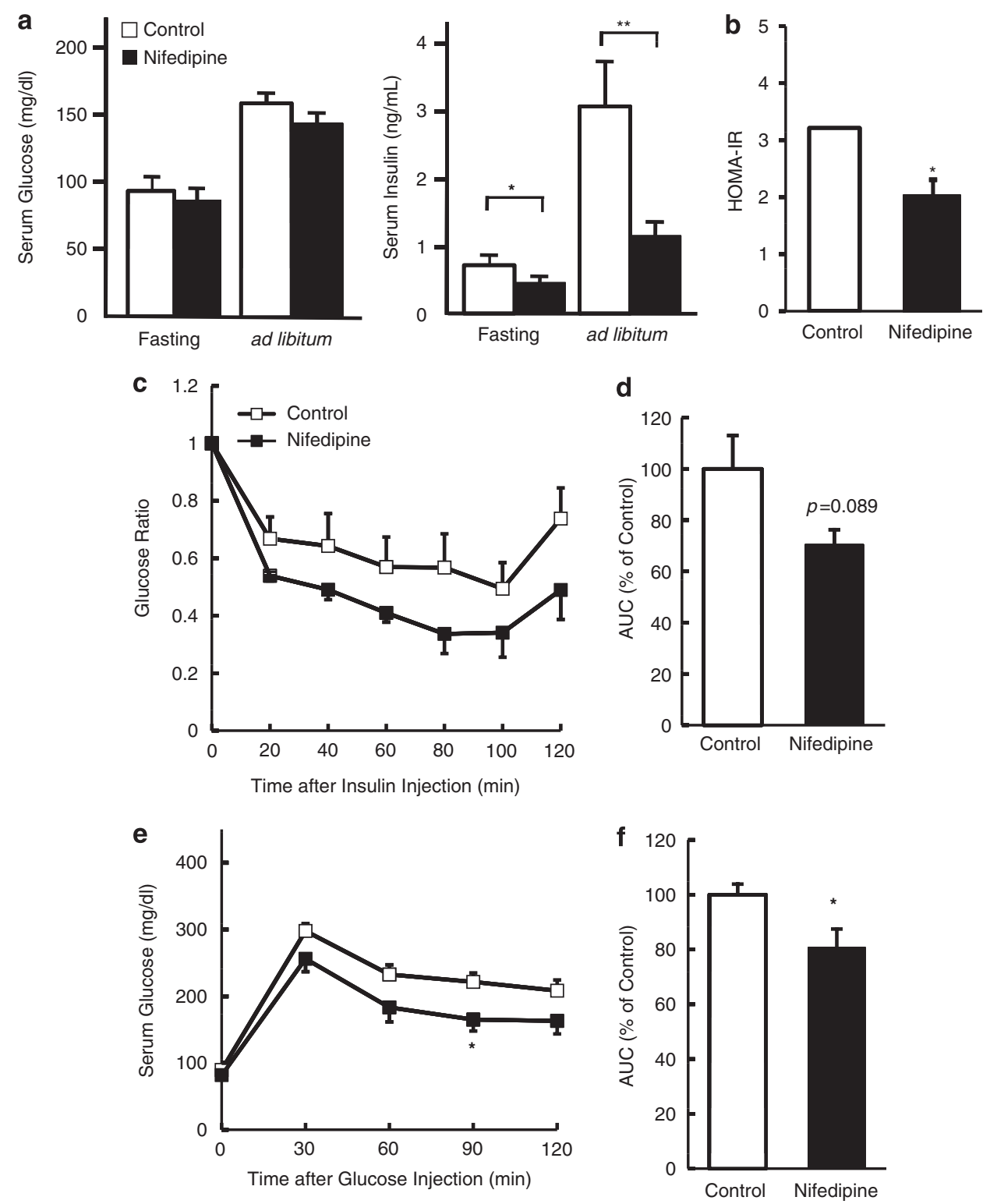

Figure 5 Effect of nifedipine on insulin sensitivity and glucose tolerance. Comparison serum glucose and insulin levels (a) and HOMA-RI index (b) after fasting (fasting) or under ad libitum feeding (ad libitum) between control and nifedipine-treated mice. Comparison of the results of insulin tolerance (c, d) and glucose tolerance (e, f) tests between control and nifedipine-treated mice ( $n=6-8$ per group). ${ }^{*} P<0.05,{ }^{* *} P<0.01$ vs. control. AUC, area under the curve.

muscle cells and may contribute to increased energy expenditure and fatty acid oxidation, although the detailed mechanism by which nonhypotensive doses of nifedipine impact obese subjects remains unclear.

Another dihydropyridine $\mathrm{Ca}$ antagonist, benidipine hydrochloride, an L-type Ca channel blocker, reportedly reduces blood pressure and inhibits weight gain in rats and dogs. ${ }^{25,26}$ Benidipine treatment also seemingly decreases body weight and body fat in obese mice models after pretreatment with monosodium-L-glutamate. ${ }^{27}$ However, only nifedipine and benidipine have been reported to have anti-obesity effects among Ca channel blockers. Therefore, the anti-obesity effect of both the drugs may be unique to these Ca channel blockers.

Peroxisomal $\beta$-oxidation reportedly functions in thermogenesis, because the first oxidation step catalyzed by fatty acyl-CoA oxidase is not coupled to ATP production, and thus energy is released as heat. ${ }^{28}$ In this study, we found that PGC- $1 \alpha$ and acyl-coenzyme A oxidase 1 expression levels were increased by nifedipine treatment.
It has recently been reported that PGC- $1 \alpha$ regulates factors required for peroxisomal $\beta$-oxidation, such as acyl-coenzyme A oxidase $1 .^{29}$ Therefore, nifedipine may exert an anti-obesity effect by upregulating PGC- $1 \alpha$, thus increasing thermogenesis mediated by acyl-coenzyme A oxidase 1 in skeletal muscle. In addition, we also observed fatty acid transport protein 1 upregulation in skeletal muscle of nifedipinetreated mice, suggesting that nifedipine enhances fatty acid transport into skeletal muscle cells.

Recently, studies have suggested that nifedipine pleiotropically activates the eNOS pathway. ${ }^{7,30}$ Indeed, Iwai et al. ${ }^{17}$ reported that nifedipine treatment reduced superoxide levels by increasing eNOS activity. However, in our study of eNOS-deficient mice, we found that the nifedipine has eNOS-independent effects on increasing the energy expenditure in skeletal muscle and insulin sensitivity. Thus, it remains unclear whether nifedipine-induced eNOS upregulation is a major pathway for countering obesity and improving insulin resistance. 
Finally, we found that nifedipine treatment enhances energy expenditure by increasing PGC- $1 \alpha$ expression in skeletal muscle. However, it is unclear whether nifedipine-induced PGC-1 $\alpha$ upregulation has a direct effect on insulin sensitivity. Previous studies have reported that expression of PGC- $1 \alpha$ is upregulated by prolonged exercise in rats ${ }^{31}$ and that moderate PGC- $1 \alpha$ overexpression in rat skeletal muscle in vivo improves insulin sensitivity. ${ }^{32}$ Future investigations could address whether prolonged exercise combined with nifedipine treatment could synergistically elevate PGC- $1 \alpha$ mRNA levels and improve insulin sensitivity in patients with obesity and/or type 2 diabetes.

\section{ACKNOWLEDGEMENTS}

We thank Mrs Shindo and Mrs Iwaki for experimental assistance. This work was supported by Grants-in-Aid for Young Scientists (No. B22790111) from the Ministry of Education, Culture, Sports, Science and Technology.

1 Berggren JR, Boyle KE, Chapman WH, Houmard JA. Skeletal muscle lipid oxidation and obesity: influence of weight loss and exercise. Am J Physiol Endocrinol Metab 2008; 294: E726-E732.

2 Willis AL, Nagel B, Churchill V, Whyte MA, Smith DL, Mahmud I, Puppione DL. Antiatherosclerotic effects of nicardipine and nifedipine in cholesterol-fed rabbits. Arteriosclerosis 1985; 5: 250-255.

3 Henry PD, Bentley KI. Suppression of atherogenesis in cholesterol-fed rabbit treated with nifedipine. J Clin Invest 1981; 68: 1366-1369.

4 Lichtlen PR, Hugenholtz PG, Rafflenbeul W, Hecker H, Jost S, Deckers JW. Retardation of angiographic progression of coronary artery disease by nifedipine. Results of the International Nifedipine Trial on Antiatherosclerotic Therapy (INTACT). INTACT Group Investigators. Lancet 1990; 335: 1109-1113.

5 Brown MJ, Palmer CR, Castaigne A, de Leeuw PW, Mancia G, Rosenthal T, Ruilope LM. Morbidity and mortality in patients randomised to double-blind treatment with a long-acting calcium-channel blocker or diuretic in the International Nifedipine GITS study: Intervention as a Goal in Hypertension Treatment (INSIGHT). Lancet 2000; 356: 366-372.

6 Verhaar MC, Honing ML, van Dam T, Zwart M, Koomans HA, Kastelein JJ, Rabelink TJ. Nifedipine improves endothelial function in hypercholesterolemia, independently of an effect on blood pressure or plasma lipids. Cardiovasc Res 1999; 42: 752-760.

7 Berkels R, Egink G, Marsen TA, Bartels H, Roesen R, Klaus W. Nifedipine increases endothelial nitric oxide bioavailability by antioxidative mechanisms. Hypertension 2001; 37: 240-245.

8 Ago T, Yang Y, Zhai P, Sadoshima J. Nifedipine inhibits cardiac hypertrophy and left ventricular dysfunction in response to pressure overload. J Cardiovasc Trans/ Res 2010; 3: 304-313.

9 Zou Y, Yamazaki T, Nakagawa K, Yamada H, Iriguchi N, Toko H, Takano H, Akazawa H, Nagai R, Komuro I. Continuous blockade of L-type Ca2+ channels suppresses activation of calcineurin and development of cardiac hypertrophy in spontaneously hypertensive rats. Hypertens Res 2002; 25: 117-124.

10 Yamagishi S, Nakamura K, Matsui T. Role of oxidative stress in the development of vascular injury and its therapeutic intervention by nifedipine. Curr Med Chem 2008; 15: $172-177$.

11 Matsui T, Yamagishi S, Takeuchi M, Ueda S, Fukami K, Okuda S. Nifedipine, a calcium channel blocker, inhibits advanced glycation end product (AGE)-elicited mesangial cell damage by suppressing AGE receptor (RAGE) expression via peroxisome proliferatoractivated receptor-gamma activation. Biochem Biophys Res Commun 2009; 385 269-272.

12 Hayashi M, Yamaji Y, Nakazato Y, Saruta T. The effects of calcium channel blockers on nuclear factor kappa B activation in the mesangium cells. Hypertens Res 2000; 23 $521-525$
13 Akaishi T, Nakazawa K, Sato K, Ohno Y, Ito Y. 4-Hydroxynonenal modulates the longterm potentiation induced by L-type $\mathrm{Ca} 2+$ channel activation in the rat dentate gyrus in vitro. Neurosci Lett 2004; 370: 155-159.

14 Arakawa M, Ishimura A, Arai Y, Kawabe K, Suzuki S, Ishige K, Ito Y. N-Acetylcysteine and ebselen but not nifedipine protected cerebellar granule neurons against 4-hydroxynonenal-induced neuronal death. Neurosci Res 2007; 57: 220-229.

15 Tuck ML, Bravo EL, Krakoff LR, Friedman CP. Endocrine and renal effects of nifedipine gastrointestinal therapeutic system in patients with essential hypertension. Results of a multicenter trial. The Modern Approach to the Treatment of Hypertension Study Group. Am J Hypertens 1990; 3: 333S-341S.

16 Radin MJ, Chu YY, Hoepf TM, McCune SA. Treatment of obese female and male SHHF/ $\mathrm{Mcc}-\mathrm{fa}(\mathrm{cp})$ rats with antihypertensive drugs, nifedipine and enalapril: effects on body weight, fat distribution, insulin resistance and systolic pressure. Obes Res 1993; 1: 433-442.

17 Iwai M, Kanno H, Inaba S, Senba I, Sone H, Nakaoka H, Horiuchi M. Nifedipine, a calcium-channel blocker, attenuated glucose intolerance and white adipose tissue dysfunction in type 2 diabetic KK-A(y) mice. Am J Hypertens 2011; 24: 169-174.

18 Tabata M, Kadomatsu T, Fukuhara S, Miyata K, Ito Y, Endo M, Urano T, Zhu HJ, Tsukano H, Tazume H, Kaikita K, Miyashita K, Iwawaki T, Shimabukuro M, Sakaguchi $\mathrm{K}$, Ito T, Nakagata N, Yamada T, Katagiri H, Kasuga M, Ando Y, Ogawa H, Mochizuki N, Itoh $\mathrm{H}$, Suda T, Oike $\mathrm{Y}$. Angiopoietin-like protein 2 promotes chronic adipose tissue inflammation and obesity-related systemic insulin resistance. Cell Metab 2009; 10: $178-188$.

19 Wallace TM, Levy JC, Matthews DR. Use and abuse of HOMA modeling. Diab Care 2004; 27: 1487-1495.

20 Miura S, Kai Y, Kamei Y, Bruce CR, Kubota N, Febbraio MA, Kadowaki T, Ezaki O. Alpha2-AMPK activity is not essential for an increase in fatty acid oxidation during lowintensity exercise. Am J Physiol Endocrinol Metab 2009; 296: E47-E55.

21 Dolphin PJ, Stewart B, Amy RM, Russell JC. Serum lipids and lipoproteins in the atherosclerosis prone LA/N corpulent rat. Biochim Biophys Acta 1987; 919: 140-148.

22 Russell JC, Ahuja SK, Manickavel V, Rajotte RV, Amy RM. Insulin resistance and impaired glucose tolerance in the atherosclerosis-prone LA/N corpulent rat. Arteriosclerosis 1987; 7: 620-626.

23 Schwartz LM, McCleskey EW, Almers W. Dihydropyridine receptors in muscle are voltage-dependent but most are not functional calcium channels. Nature 1985; 314: 747-751.

24 Sun X, Zemel MB. Leucine and calcium regulate fat metabolism and energy partitioning in murine adipocytes and muscle cells. Lipids 2007; 42: 297-305.

25 Tanaka H, Waki Y, Ito R, Kashitani S, Yamanami S, Saijo T, Ikegami J, Hara T. Toxicity study of benidipine hydrochloride (1 ${ }^{\text {st }}$ report): acute toxicity in mice and rats, subacute and chronic oral toxicity studies of benidipine hydrochloride in rats. Clin Rep 1990; 24: 1045-1109.

26 Tanaka H, Waki Y, Ikenaga T, Kashitani S, Yamanami S, Saijo T, Ikenaga J, Hara T. Toxicity study of benidipine hydrochloride ( $2^{\text {nd }}$ report): acute, subacute and chronic oral toxicity studies of benidipine hydrochloride in dogs. Clin Rep 1990; 24: 1811-1860.

27 Yoshida T, Umekawa T, Wakabayashi Y, Sakane N, Kondo M. Mechanism of anti-obesity action of benidipine hydrochloride in mice. Int J Obes Relat Metab Disord 1994; 18: 776-779.

28 Goglia F, Liverini G, Lanni A, lossa S, Barletta A. Morphological and functional modifications of rat liver peroxisomal subpopulations during cold exposure. Exp Biol 1989; 48: 127-133.

29 Bagattin A, Hugendubler L, Mueller E. Transcriptional coactivator PGC-1alpha promotes peroxisomal remodeling and biogenesis. Proc Natl Acad Sci USA 2010; 107: 20376-20381.

30 Yamamoto E, Nakamura T, Kataoka K, Tokutomi Y, Dong YF, Fukuda M, Nako H, Yasuda O, Ogawa H, Kim-Mitsuyama S. Nifedipine prevents vascular endothelial dysfunction in a mouse model of obesity and type 2 diabetes, by improving eNOS dysfunction and dephosphorylation. Biochem Biophys Res Commun 2010; 403: 258-263.

31 Goto M, Terada S, Kato M, Katoh M, Yokozeki T, Tabata I, Shimokawa T. cDNA cloning and mRNA analysis of PGC-1 in epitrochlearis muscle in swimming-exercised rats. Biochem Biophys Res Commun 2000; 274: 350-354.

32 Benton CR, Nickerson JG, Lally J, Glatz JF, Luiken JJ, Graham TE, Heikkila JJ, Bonen A. Modest PGC-1alpha overexpression in muscle in vivo is sufficient to increase insulin sensitivity and palmitate oxidation in subsarcolemmal, not intermyofibrillar, mitochondria. J Biol Chem 2008; 283: 4228-4240.

Supplementary Information accompanies the paper on Hypertension Research website (http://www.nature.com/hr) 